\title{
The response of vital rates to harvest fluctuations in pre-industrial Sweden
}

\author{
Rodney Benjamin Edvinsson ${ }^{1,2}$ (B)
}

Received: 10 September 2015/ Accepted: 10 May 2016/Published online: 26 May 2016

(C) The Author(s) 2016. This article is published with open access at Springerlink.com

\begin{abstract}
This study examines whether there was a Malthusian equilibrium mechanism in Sweden in the pre-industrial period. A unique data set on harvests, deaths, marriages and births going back to 1630 is used to calculate cumulative elasticities of vital rates with respect to harvest. While earlier studies have mostly focused on the impact of real wage, this study uses the calorie content of per capita harvests as an indicator of living standards. It finds that there indeed was a response of vital rates to harvest fluctuations, but there were important structural breaks. While positive checks attenuated after 1720, preventive checks were strengthened. After 1870 preventive checks disappeared, and possibly also positive checks. The results are robust to different models and trend specifications, with one crucial difference: while the distributed lag model shows that positive checks were significant up to 1920, the SVAR model shows that positive checks disappeared after 1870 .
\end{abstract}

Keywords Sweden · Economic history · Demography · Agriculture · Malthus · Mortality · Fertility

JEL Classification N13 $\cdot$ N34 $\cdot$ N43 $\cdot$ N53

\section{Introduction}

The relation between population and economic development has been a central theme in economic and social theory since the eighteenth century. The question of the causal connection between economic and population growth in agrarian society

Rodney Benjamin Edvinsson

rodney.edvinsson@ekohist.su.se

1 Department of Economic History, Stockholm University, Stockholm, Sweden

2 Swedish Collegium for Advanced Study, Uppsala, Sweden 
is still unresolved. As Diebolt $(2016,1)$ notes "cliometrics can proceed only if the nature of causal explanation has been resolved." There are opposing interpretations. While most Malthusians emphasize diminishing returns on natural resources, producing mortality crises, many of their critics point out that population growth by itself generated advances in technology.

Malthus' concept of positive checks is usually operationalized as the response of death rates to fluctuations in living standards (Galloway 1988, 291; Klemp and Møller forthcoming, 5). His concept of preventive checks is usually operationalized as the response of marriage or birth rates. The unified growth theory, which aims to model both technological progress and demographic transition in the eighteenth and nineteenth centuries endogenously, predicts that while preventive checks were initially strengthened, positive checks were weakened once technological progress took off (Galor and Weil 2000; Pfister and Fertig 2010). However, what exactly a Malthusian model entails is a topic for an ongoing discussion, and there is no reason to interpret the Malthusian mechanism in just one way. In fact, Mokyr and Voth (2008, 14-15) suggest that the Malthusian model rests on two assumptions: (1) that population growth reacted positively to living standards through preventive and positive checks and (2) that living standards were negatively related to the size of the population. They contrast two Malthusian versions against each other. In its strongest form, it predicts stagnant per capita income without shifting mortality and fertility schedules and stagnant population in the absence of technological advance. In its weaker version, it accentuates equilibrium mechanisms, i.e., the positive and preventive checks on population rather than the specific outcomes.

The analysis of the development of preventive and positive checks is highly dependent on which variables are chosen and not only on the statistical model. Earlier international research on the effect of economic stress on the population in the pre-industrial period has largely relied on real wages or grain prices as indicators of living or nutritional standards (Wrigley and Schofield 1989, pp. 368-384; Galloway 1988, 1994; Lee and Anderson 2002; Nicolini 2007; Bengtsson and Broström 2011; Bengtsson and Ohlsson 1985; Dribe 2003; Crafts and Mills 2009; Pfister and Fertig 2010; Chiarini 2010; Klemp 2012; Møller and Sharp 2014; Klemp and Møller forthcoming). ${ }^{1}$ Malthusians often point to the development of real wages, which fell from the late Middle Ages to the early nineteenth century, to advance their main proposition that population growth outpaced production (Allen 2001; Clark 2007). Anti-Malthusians tend to disagree (Persson 2008). Maddison (2007, 308) contends that wages cannot be used as indicators of living standards since they do not represent a macroeconomic variable. The volatility in grain prices was also affected by market integration, not only by harvests (Edvinsson 2012). While there was a strong correlation between movements in grain prices and harvests in the early modern period, this relation attenuated during the nineteenth and twentieth centuries due to improved international market integration. Recently, Dribe, Olsson and Svensson (2011) demonstrate that at the local level in southern

\footnotetext{
${ }^{1}$ Eckstein et al. 1984 and Larsen 1987 use a harvest series to investigate the impact on vital rates in Sweden, but this harvest series is deficient for the period before 1865 (Edvinsson 2009). Dribe et al. (2011) analyze the mortality response to grain output derived from tithes, but at the local level in southern Sweden.
} 
Sweden, grain output had a different impact on mortality than grain prices, since the latter reflected conditions in surrounding areas.

Vital statistics are data on the births, deaths, marriages, divorces, etc. Vital rates are calculated by dividing these vital statistics to the total population. This paper utilizes recently constructed annual series of Swedish vital rates and harvests to estimate the elasticities of vital rates back to 1630 . The whole period $1630-1870$ is put into investigation, although a comparison is also made with 1871-1920. Harvest data are transformed into the per capita production of calories. The "Appendix" explains the data sources in detail.

In this paper, the elasticities of vital rates are calculated as cumulative elasticities, since the impact of harvest could be delayed. In the first step, a simple distributed lag model (DLM) and an ARMAX (autoregressive moving average with exogenous input) model are presented. Subsequently, a structural vector autoregression model (SVAR) is applied to estimate structural impulse response functions that can be given a causal interpretation (Eckstein et al. 1984; Nicolini 2007). The empirical evidence supports the view that there was a short-term Malthusian equilibrium mechanism in the Swedish pre-industrial economy, even if the mechanism changed over time. The question of whether there was a medium- or long-term Malthusian equilibrium mechanism is, however, outside the scope of this study. A short-term mechanism does not necessitate a long-term one, even if there is usually a connection between the two under ceteris paribus.

\section{An overview of the data}

\subsection{Death rates}

When comparing seventeenth century Sweden with other countries for which data on vital rates exists, Sweden stands out for the occurrence of severe mortality crises. Figure 1 compares the crude death rate in Sweden, England and northern Italy. The

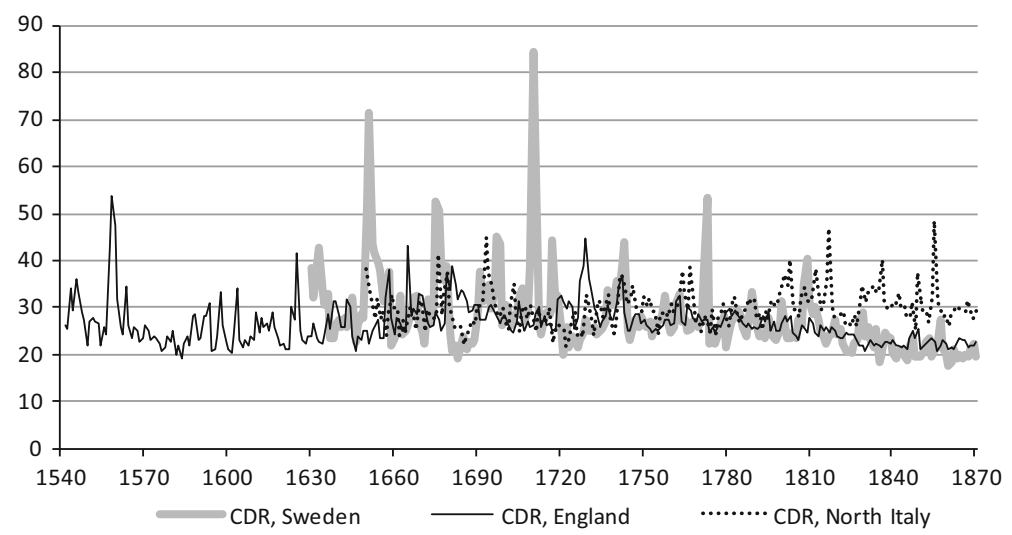

Fig. 1 Crude death rate in Sweden, England and northern Italy 1540-1870 Sources: Galloway (1994), Edvinsson (2015), and Wrigley and Schofield (1989) 
English data, which are reconstructed by Wrigley and Schofield (1989), go back to 1541 , and the data for northern Italy to 1650 . Although data also exist on Germany back to the seventeenth century, it has not been made available in published form (Pfister and Fertig 2010). Data on vital rates in rural France exist back to 1670, but only for persons aged five and older (Rebaudo 1979). In Sweden, the crude death rate was highest in 1710, at 84 per 1000, the last outbreak of the bubonic plague in Sweden. The second highest level was reached in 1651 , at 72 per 1000. In comparison, the highest level in England after 1541 was in 1558, at 54 per 1000, and in northern Italy after 1650 , in 1693 , at 45 per 1000 . Still in 1773 , the crude death rate rose above 50 per 1000 in Sweden, while in England after 1558 the rate never rose above that level.

In Sweden, there were two important breaks in mortality: around 1720, after the end of the Great Northern War (1700-1721), resulting in the victory of Russia over the Swedish Empire, and around 1820, when Sweden entered its long period of peace and the average death rates started to decline. Up to around 1720, the average crude death rate was higher in Sweden than in England and northern Italy. After 1720, it fell to the level in England. According to the data of Wrigley and Schofield, English death rates did not decline in the first half of the eighteenth century. After 1812, the Swedish crude death rate never rose above 30 per 1000 , while that was the average level in northern Italy up to the 1860s. By the 1840s, the average crude death rate in Sweden fell below the average in England, despite that Sweden was poorer. Mortality affected various groups differently (Bengtsson 2004), but that issue is not considered here.

Figure 2 compares the volatility of the crude death rate in the three areas, measured as the 40-year moving standard deviation of the annual logarithmic change (choosing another moving standard deviation period does not change the overall picture). The paths are clearly different in the three areas. In 1650-90, volatility was equal in England and northern Italy, whereas in Sweden it was substantially higher. While volatility decreased in England after 1690, and in Sweden after 1720, the volatility in northern Italy did not change. By the first half of

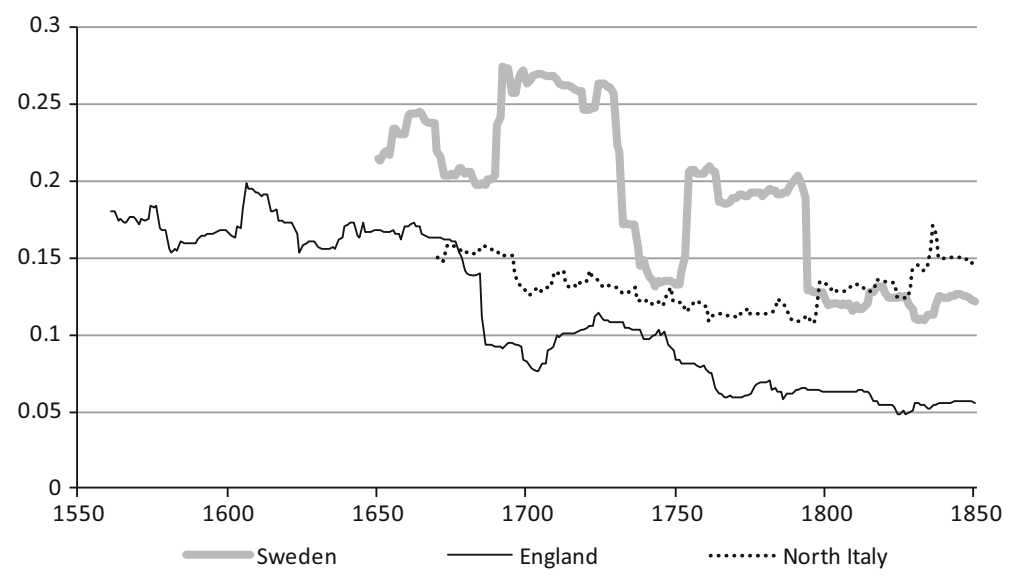

Fig. 2 Forty-year moving standard deviation of the logarithmic annual changes in crude death rates in Sweden, England and northern Italy Sources: See Fig. 1 and "Appendix" 
the nineteenth century, the volatility in Sweden decreased below the level in northern Italy. Sweden and England are therefore comparable in terms of a longterm decline in the occurrence of mortality crises during the early modern period, but Sweden lagged 100-150 years behind the development in England.

The above comparison rests on the assumption that the underlying data are not biased, but there are competing interpretations of the demographic development. The demographic data for Sweden going back to 1630 are based on an earlier study by the Swedish historian Lennart Andersson Palm. As explained in the "Appendix," the present study uses a revision to the series, which upgrades the size of population and the vital rates especially for the earlier years (Edvinsson 2015). Razzel (1993, 752) argues that the assumption of Wrigley and Schofield of a burial accuracy of 100 per cent is unrealistic and that the actual mortality levels could be much higher. He suggests that in reality there was a decline in English death rates in the first half of the eighteenth century, which would make the development in England comparable to Sweden.

\subsection{Birth rates}

Figure 3 presents the development of the crude birth rate in the three areas during the same period as in Fig. 1. This is the period before the second phase of the demographic transition, i.e., before fertility declined. Several Swedish historians argue that there was another, hidden, demographic transition between the seventeenth and eighteenth centuries, which increased the age for marriages. Larsson (2006, 145-146 and 205) shows that the average age of first marriage among women increased from around 24 years to around 26 years during the first two decades of the eighteenth century and stabilized at this level after a temporary drop in the 1730s. Higher age of marriage indicates strengthened preventive checks. When compared to the quite sharp medium-term fluctuations in England and northern Italy, the fall in the crude birth rate in the early eighteenth century Sweden

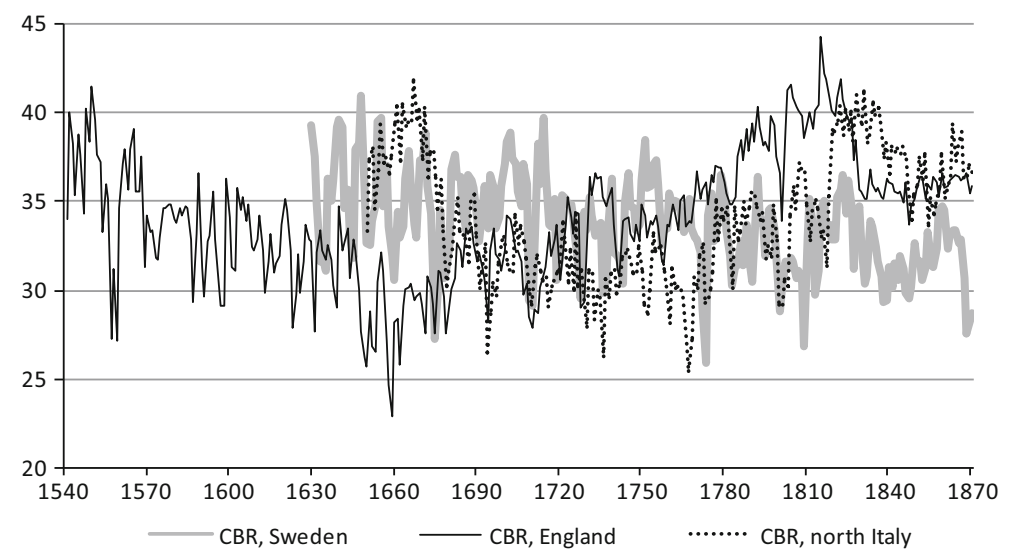

Fig. 3 Crude birth rate in Sweden, England and northern Italy 1540-1870 Sources: See Fig. 1 and "Appendix" 


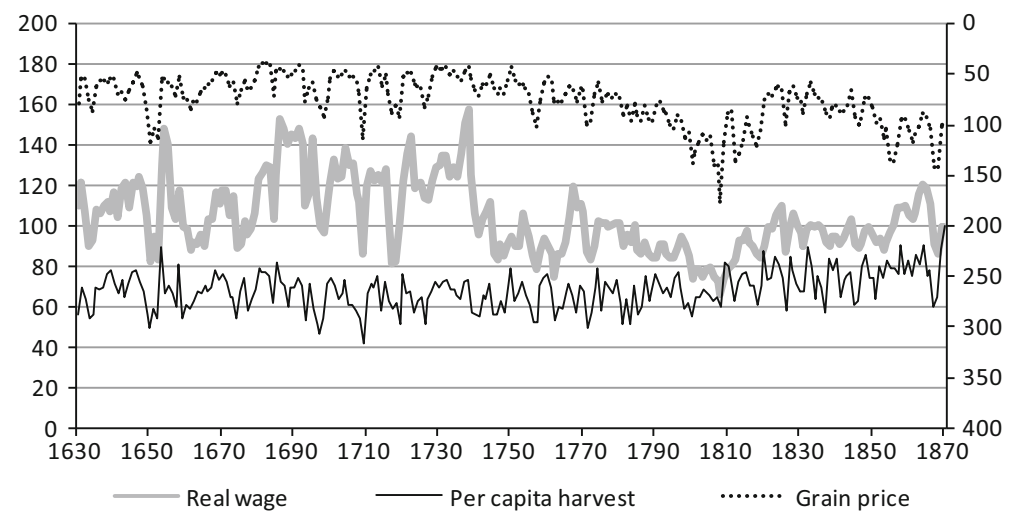

Fig. 4 Real wage (left scale), calories per capita harvest (left scale) and grain price (right scale) in Sweden 1630-1870 $(1870=100)$ Source: See "Appendix"

was not so large. However, Razzel $(1993,745)$ argues that the rise in birth rates in the eighteenth century according to the data of Wrigley and Schofield (see Fig. 3) could be spurious as well.

\subsection{Living standards}

Living standards in the pre-industrial period can be measured using different indicators. Figure 4 presents the development of the real wage, calorie per capita harvest and the grain price in Sweden 1630-1870 (see the "Appendix"). 1870 is chosen as a benchmark and set equal to 100. The figure shows that several of the mortality crises were preceded by negative shocks to the living standards, whichever indicator is chosen. Most notably both the mortality crisis in the early $1650 \mathrm{~s}$ and the early $1710 \mathrm{~s}$ were preceded by severe harvest failures, low real wages and high grain prices.

The mortality crisis in $1772-1773$ was also preceded by falling livings standards. Official statistics on the causes of deaths show that in 1772-1773 were the only years since 1749 when the number of deaths due to starvation reached above 1000 . However, various infectious diseases, such as dysentery, were a more common cause of deaths. Reduced resistance due to malnutrition and increased travels when people searched the country for food and work contributed to the spread of these diseases (Willner 2005, 41).

By the nineteenth century, it is not as clear whether shocks to the living standards were followed by mortality crises. Most notably the severe harvest failure in 1867 only slightly raised mortality (mostly affecting northern Sweden), ${ }^{2}$ from 19 per 1000 in 1865 to 22 per 1000 at its peak in 1869. In comparison, in neighboring Finland the outcome was different. At the peak of the Finnish famine, in 1868, the crude death rate reached 78 per 1000 (Ó Gráda 2001, 576), a level which in post1630 Sweden was only surpassed once, in 1710.

\footnotetext{
2 Nelson 1988, 82.
} 
The indicators of livings standards tended to move together, but there are divergences especially for the medium-term fluctuations. For example, the grain prices were at their highest level, and real wages at their lowest level in the early nineteenth century. Nevertheless, the development of per capita harvests or the crude death rates was different. Per capita harvest is a more direct indicator of nutrition standards. For Sweden, earlier research shows that there is a lack of strong congruence between real wage and macroeconomic conditions. Jörberg (1972, vol. 2,343 ) notes that "the fall in the real wages of day workers provides no information on the general economic situation of agriculture during the later part of the eighteenth century." It is likely that the fall was counteracted by increased labor input per inhabitant. While real wage was very high in 1690-1730 compared to the rest of the eighteenth century, Morell (1989) demonstrates low levels of calorie intake in Swedish "hospitals" in this period compared to the earlier and later decades.

In his original demographic theory, Malthus (1985, 183-195) related population growth to food production rather than to per capita income or wages. He focused on the "produce of land," while he viewed increases in "manufactured produce" as immaterial to the well-being of the population at large. Even though the Industrial Revolution has later disproved Malthus' view of the role of manufacturing, his argument has some relevance for an agrarian society. In industrialized countries, there is a positive correlation between changes in living standards and fertility (Galloway 1994, 4), but this should not be interpreted as a Malthusian mechanism, since it is not the lack of food per se that poses limits on fertility today. The key indicator of food production is annual harvest. Even though food production also includes animal husbandry, harvest fluctuations largely affected the latter as well. Alternative productivity measures that have been employed by economic historians include yield per hectare, labor productivity and total factor productivity (Hoffman 1991, 777-780), but per capita harvests are more closely related to the nutrition standard. Furthermore, the most adequate measure of harvest, when related to vital rates, is its calorie content.

\section{Models treating harvest as exogenous}

One way to study the Malthusian equilibrium mechanism is to calculate cumulative elasticities of vital rates (Bengtsson and Ohlsson 1985, 316; Voigtländer and Voth 2009, 249). The (short-term) Malthusian preventive check on population implies that the per capita harvest elasticities of birth and marriage rates are positive. The presence of positive checks entails that the elasticity of the death rate is negative. The analysis in this study is based on the logarithms of the calorie content of per capita harvests $(h)$, crude death rates $(d)$, marriage rates $(m)$, and crude birth rates (b). There are several methods to estimates these elasticities. This section presents two models that treat harvest as exogenous, i.e., the distributed lag model (DLM) and the ARMAX model. In the subsequent section a SVAR model is applied, which treats harvest as an endogenous variable, i.e., it is assumed that per capita harvest can be affected by the vital rates, although with a time lag. 
First, it is important to determine whether there are stochastic or deterministic trends in the underlying series. There were substantial shifts in the vital rates and per capita production of calories over time. We first investigate whether any of the series contain a unit root, i.e., if any series contains a stochastic trend. For the period 1630-1870, the DF-GLS test strongly (at a 1 percent level) rejects the null hypothesis of a unit root for the logarithms of per capita calorie production, death rates, birth rates, and marriage rates, if a time trend is allowed, and irrespective of the information criterion used. However, without a time trend, the null hypothesis of a unit root cannot be rejected for the logarithm of birth rates. This entails that at least for birth rates a trend component should be included, while other series may be stationary. The lack of stochastic trends, at least when including a time trend, entails that cointegration models are not suitable (stationary series are always cointegrated).

Since we may suspect that the various variables contain a deterministic trend, the correct method is to analyze deviations from trend rather than first differences. Modeling the appropriate deterministic trend is problematic, and various specifications can generate different results. In this section, two specifications are applied: a polynomial of time is included and the series are filtered using a HP filter, setting $\lambda$ equal to 10,000 . A high value of $\lambda$ is necessary, to avoid spurious cycles. Usually the values of 100 or 6.25 are used to investigate business cycles, but we here want to investigate movements around a more long-term trend (there is no mathematical reasons to apply just one value for $\lambda$ in all studies). A time polynomial is chosen up to the second degree.

In addition, possible structural breaks are investigated. For this purpose, the timing of possible breaks is assumed to be known. There are econometric methods allowing the determination of breaking points within the model. The significance level for deciding whether there was a break or not is then higher, and the result less certain. These methods are not applied in this study, since possible breaks are suggested in the literature (see discussion above). These are: 1720, 1820, 1870 and 1920. Around 1720, the Great Northern War ended, and the Age of Liberty (1718-1772), a period of parliamentary governance, began. After 1820, Sweden was transformed from a net importer of grains to a net exporter (Åmark 1915, 354-355). 1870 is often considered as the beginning of Swedish industrialization. After 1920, agriculture stopped having any substantial impact on the aggregate economy (Edvinsson 2012, 2013a, b, 2015).

The simplest way to investigate the elasticities of vital rates is to apply a distributed lag model, $\operatorname{DLM}(s)$, where $s$ is the number of lags in the exogenous variables:

$$
y_{t}=\mu+f(t)+\sum_{i=0}^{s} b_{i} h_{t-i}+\eta_{t}
$$

$\eta_{t}$ is the error term, which is not necessarily white noise, since there could be autocorrelation. $y_{t}$ is the logarithm of the vital rate, and $h_{t-i}$ the logarithm of per capita harvest in year $t-i$. $f(t)$ is a time polynomial. For the filtered series, no time polynomial is included. 
The cumulative elasticity can be interpreted as the increase in the expected value of the dependent variable following a one-unit change in the expected value of the independent variable, or as the partial derivative $\partial \mathrm{E}\left[y_{t}\right] / \partial \mathrm{E}\left[h_{t}\right]$. This is also the longrun multiplier:

$$
\text { Cum }=\frac{\partial \mathrm{E}\left[y_{t}\right]}{\partial \mathrm{E}\left[h_{t}\right]}=\sum_{j=0}^{s} b_{i}
$$

In the DLM, harvest is assumed to be an exogenous variable, affecting the various vital rates at different lags. One problem is how to handle extreme values. Severe harvest failures in Sweden were often followed by plagues (Larsson 2006, 93-120). The extreme changes in mortality levels constituted an important feature of the Malthusian equilibrium mechanism and should therefore not be abstracted from the model. Although wars could be viewed as exogenous, there are reasons to consider them part of an endogenous mechanism within a Malthusian model, especially when considering the impact of war on living standards via increased death rates. A problem with including an exogenous war dummy is that in the period 1630-1720 Sweden was at war most of the years.

Table 1 presents six different regressions based on a $\operatorname{DLM}(3)$, with data for the period 1630-1870. Three lags of harvest are included, since for some, but not all, specifications the third lag is significant. A problem with the DLM is that autocorrelations in the error terms can be detected for all the specifications. Therefore, the significance levels of OLS are not appropriate. The table instead displays results using Newey-West standard errors with one lag. The table presents cumulative elasticities, $\mathrm{Cum}_{\text {period}}$, by summing up the coefficients for the harvest and its lags.

The two different specifications of the trend yield very similar results, for the regressions where death rates is the dependent variable. For the period 1630-1870, the cumulative elasticity is -1.1 to -1.2 , entailing that just a $1 \%$ permanent decline in harvests caused death rates to (ceteris paribus) permanently increase by 1.1-1.2\%. Harvest lagged by 1 year had a very substantial effect on current death rates. However, there was also an effect of current year's harvest on the current year's death rates, despite that harvests occurred in September.

For crude birth and marriage rates, the result is likewise similar for the two trend specifications. For the period 1630-1870, the cumulative elasticities of marriage and crude birth rates are estimated to be around 0.4 in both specifications. It should be considered that the overall volatility of death rates was higher than for birth and marriage rates, which may explain that the preventive checks were weaker than the positive checks.

As a further robustness check, Table 1 also presents the cumulative elasticities, if only two lags are included in the regressions. It shows that the result is very similar to the regressions with three lags.

These results demonstrate that there was a distinct short-term Malthusian mechanism before the industrial breakthrough in the 1870s. All vital rates were affected by harvest fluctuations in the same direction as predicted by various Malthusian models. 


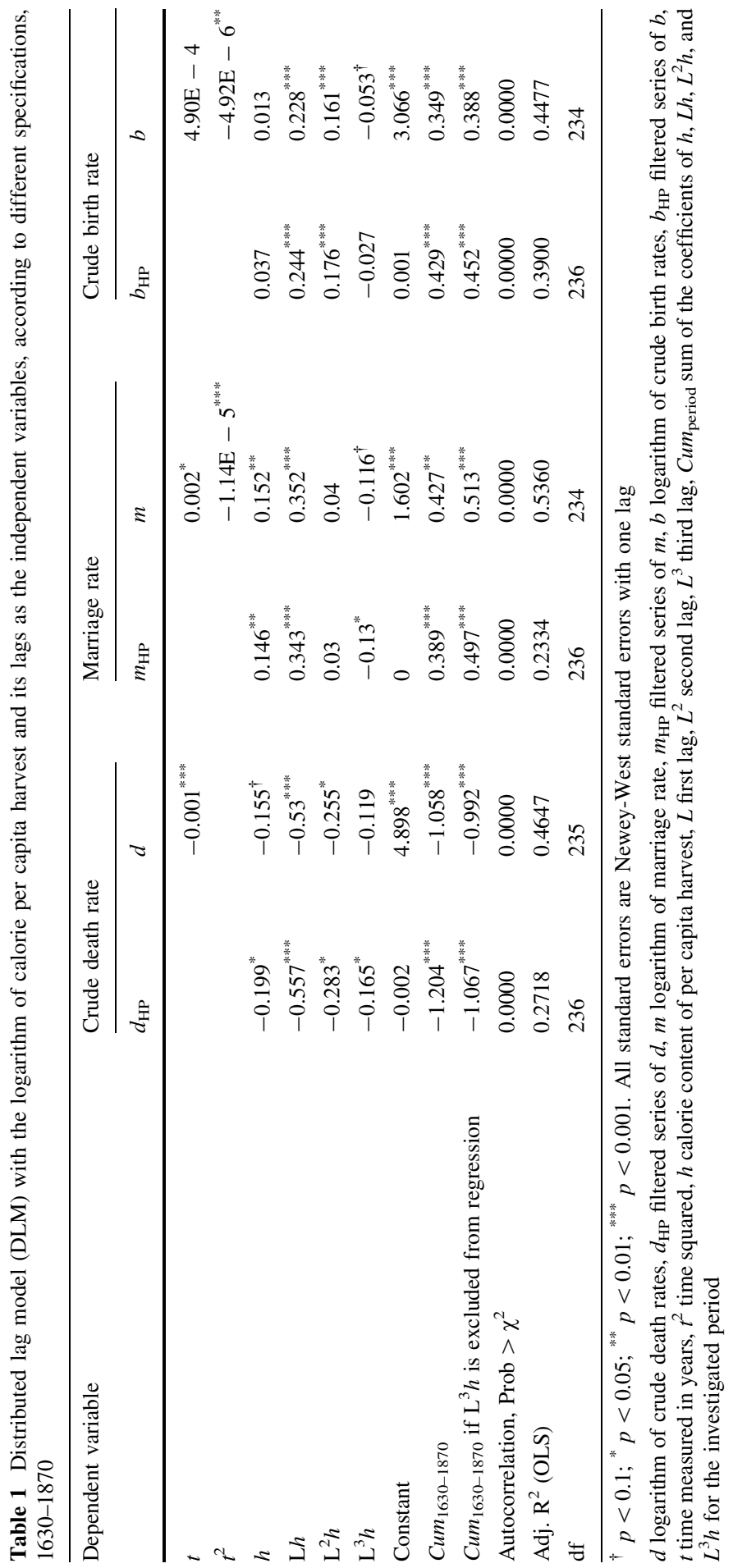


In Table 2, the investigated period is divided into two, 1630-1720 and 1721-1870. In addition, the period 1871-1920 is also included. Tests were performed to asses whether there occurred any structural breaks in the cumulative elasticities. The result is not completely comparable to Table 1. Although the time polynomials are modeled with the same powers, the time polynomial is assumed to be different in the two sub-periods. For death rates, both specifications entail that there was a significant decline in the cumulative elasticity. This mirrors the decline in the volatility of death rates. For birth rates, there is no indication that there was any shift. However, for marriage rates both specifications entails that cumulative elasticity was strengthened after 1720. 1720 therefore seems to be an important structural break in the Malthusian mechanism; while the positive checks attenuated, the preventive checks strengthened.

Somewhat surprising is that the elasticity of death rates in the period 1871-1920 was as strong as in 1721-1870. For marriage and birth rates, there was clearly a structural break occurring in 1871 for both specification.

There could be further breaks in the time series. For example, it is possible that a break occurred in 1821. Performing the same analysis as in Table 2, there is no indication of any weakening of the Malthusian mechanism occurring in that year. In fact, if there was a shift, it rather indicates a strengthening, but the difference is only significant for birth and marriage rates, and not for death rates. No results of this analysis are presented here.

Time series models are often very sensitive to the underlying assumptions. It is therefore important to investigate whether more complicated models could render other results.

The problem with Eq. (1) is that there is autocorrelation in the error term. In the ARMAX model, the error term is modeled as an ARMA process. Equation (1) is then termed the measurement equation, while the so-called transition equation is (where $\varepsilon_{t}$ is white noise, and $\phi(\mathrm{L})$ and $\theta(\mathrm{L})$ are lag polynomials):

Table 2 Estimated cumulative elasticity according to a DLM in various sub-periods 1630-1920

\begin{tabular}{|c|c|c|c|c|c|c|}
\hline \multirow[t]{2}{*}{ Dependent variable } & \multicolumn{2}{|c|}{ Crude death rate } & \multicolumn{2}{|c|}{ Marriage rate } & \multicolumn{2}{|c|}{ Crude birth rate } \\
\hline & $d_{\mathrm{HP}}$ & $d$ & $m_{\mathrm{HP}}$ & $m$ & $b_{\mathrm{HP}}$ & $b$ \\
\hline Cum $_{1630-1720}$ & $-1.535^{* * *}$ & $-1.492^{* * *}$ & 0.224 & 0.234 & $0.378^{* * *}$ & $0.324^{* *}$ \\
\hline $\mathrm{Cum}_{1721-1870}$ & $-0.676^{* * *}$ & $-0.85^{* * *}$ & $0.660^{* * *}$ & $0.684^{* * *}$ & $0.511^{* * *}$ & $0.515^{* * *}$ \\
\hline $\mathrm{Cum}_{1871-1920}$ & $-0.732^{* * *}$ & $-0.701^{* *}$ & -0.103 & $-0.365^{*}$ & -0.158 & -0.002 \\
\hline $\begin{array}{l}\text { Significance test of the } \\
\text { equality of Cum } \text { Cum-1720 }_{1630-170} \\
\text { and } \text { Cum }_{1721-1870}\end{array}$ & 0.0069 & 0.0406 & 0.0358 & 0.0281 & 0.2731 & 0.1450 \\
\hline $\begin{array}{l}\text { Significance test of the } \\
\text { equality of Cum } \\
\text { and Cum } 1871-1920\end{array}$ & 0.8401 & 0.5896 & 0.0015 & 0.0000 & 0.0000 & 0.0005 \\
\hline Power of time polynomial & 0 & 1 & 0 & 2 & 0 & 2 \\
\hline
\end{tabular}




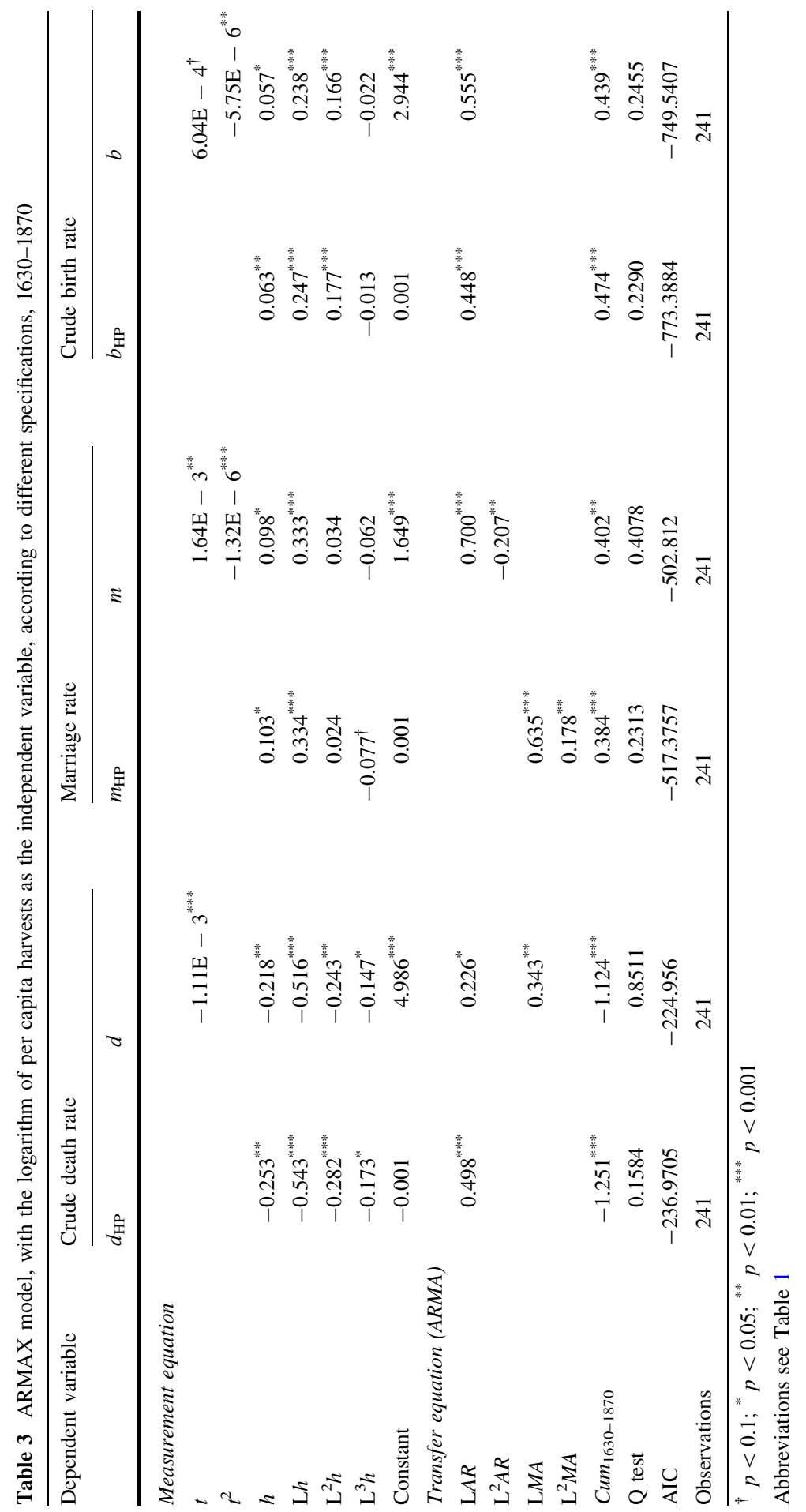




$$
\varphi(\mathrm{L}) \eta_{t}=\theta(\mathrm{L}) \varepsilon_{t}
$$

The cumulative elasticity can be estimated in the same way as for the DLM. Table 3 presents the relevant regressions, which are the equivalent to the regressions in Table 1. The ARMA specifications are determined based on the minimization of the Akaike information criterion. The $\mathrm{Q}$ test shows that there is no remaining autocorrelation in the error term. Interestingly, the estimated coefficients were almost the same as in Table 1, although the cumulative elasticities for death and birth rates were somewhat stronger.

\section{Estimating a SVAR model}

A VAR model takes into account the endogenous relations between variables. For example, we may suppose that good harvests caused higher birth rates, which decreased per capita harvest, which in turn reduced the number of birth rates at later periods. Treating harvests as unaffected by the other variables would in this hypothetical example entail that such indirect effects are not taken into account. The problem is how to determine the contemporaneous relations. In the reduced VAR model, the contemporaneous effects remain unknown. The reduced VAR model can only be used for prediction and cannot be given any causal interpretation.

In the reduced VAR model, each variable is linear combination of the lagged values of itself and the lagged values of the other variables included in the model:

$$
\mathbf{y}_{t}=\mu+\mathbf{C t}_{t}+\sum_{k=1}^{l} \boldsymbol{\Phi}_{k} \mathbf{y}_{t-k}+\varepsilon_{t}
$$

$\mathbf{y}_{t}$ is here a four-element column vector, where the elements consist of the natural logarithms of the calorie content of per capita harvest, the crude death rate, the marriage rate and the crude birth rate. $\boldsymbol{\mu}$ is a four-element column vector of constants, $\mathbf{C}$ is a $4 \times r$ matrix of the coefficients for the time polynomial, $\mathbf{t}_{t}$ is the $r$ element vector of time up to the $r$ th power, $\boldsymbol{\Phi}_{k}$ represents $4 \times 4$ matrices of coefficients, $\boldsymbol{\varepsilon}_{t}$ is a four-element column vector of the white noise process and $l$ is the number of lags included in the VAR model. In the structural VAR, a causal interpretation can be made. This entails that we multiply expression (4) by a $4 \times 4$ matrix, A, whose diagonal consists of ones:

$$
\mathbf{A} \mathbf{y}_{t}=\mathbf{A} \mu+\mathbf{A} \mathbf{C t} t+\sum_{k=1}^{l} \mathbf{A} \boldsymbol{\Phi}_{k} \mathbf{y}_{t-k}+\mathbf{A} \varepsilon_{t}
$$

While the elements of $\varepsilon_{t}$ are not necessarily independent from each other, the shocks contained in the vector of $\mathbf{A} \boldsymbol{\varepsilon}_{t}$ are by construction orthogonal. The problem is that structural VAR cannot be derived from the reduced VAR, due to the endogenous relations between the variables. However, a solution can be imposed. For example, in a recursive VAR, there is an order between the variables. A then consists of zeros above its diagonal. The zeros above the diagonal entail that there is 
no current effect of variable $\mathrm{X}_{m}$ on variable $\mathrm{X}_{n}$ if $m$ is larger than $n$, where $m$ and $n$ are the orders of the variables. The problem with imposing a solution, for example, an order between variables, is that this solution is to some extent ad hoc and should therefore be motivated theoretically.

$\mathbf{A} \boldsymbol{\varepsilon}_{t}$ in Eq. (5) can also be written as $\mathbf{B} \mathbf{v}_{t}$, where $\mathbf{v}_{t}$ is the vector of orthogonalized shocks, while $\mathrm{E}\left[\mathbf{v}_{t} \mathbf{v}_{t}{ }^{\prime}\right]$ is the identity matrix, I. B is a diagonal matrix. Therefore, the vector $\mathbf{B} \mathbf{v}_{t}$ is also orthogonalized.

Impulse response functions and cumulative impulse response functions are a way to graphically illustrate the impact of one variable on another over several periods. The structural impulse response function also lends support for causal analysis.

In this study, the following causal order is assumed: per capita harvests, crude death rates, marriage rates and crude birth rates. Harvests should have been causally prior to any of the other three variables. Although in the Malthusian model vital rates also affect harvests, this is more of a long-term effect. In the SVAR model used in this study, vital rates are allowed to causally affect harvests after a 1-year lag. High death rates were often followed by higher marriage rates within a shorter time span than 1 year. Marriage rates in the beginning of the year most likely affected birth rates at the end of the same year.

The first step is to assess the number of lags in the VAR, which can be derived from various information criteria. The appropriate lag order is always difficult to set. Two trend specifications are investigated. In the specification with a quadratic time polynomial, HQIC and SBIC indicate that only one lag should be included. However, FPE and AIC indicate three lags. For the filtered series, the information criteria yield the same result.

The next step is to perform various diagnostic tests on the underlying VAR model. Testing for the stability shows that all eigenvalues of the companion matrix lie within the unit circle, irrespective of whether the underlying VAR model contains one or three lags. The stability condition is met also when no trend is assumed. Unfortunately, the Lagrange multiplier test shows that the null hypothesis of no first-order residual autocorrelation is rejected at a $1 \%$ level, whichever specification is used (see Table 4). Therefore, there could be a misspecification in the model. The problem lies in the assumption of no structural change during the whole period $1630-1870$.

If we instead construct separate VAR models for different sub-periods, there are instances where the null hypothesis of no first- or second-order autocorrelation is not rejected. Table 4 summarizes the Lagrange multiplier test of different specifications of the VAR model. For the period 1630-1720, only in the specifications with no trend is the null hypothesis of no residual first- and second-order autocorrelation not rejected. For the periods 1721-1870 and 1871-1920, the Lagrange multiplier test indicates that there is no residual autocorrelation for the specification with a quadratic time polynomial with three lags. In this study, the choice therefore falls on a VAR with three lags, for the period 1630-1720 with no trend, and for the periods 1721-1870 and 1871-1920 with a quadratic time polynomial. The filtered series are not considered since for the period 1630-1720 both specifications of the number of lags included indicates residual first-order autocorrelation. 
Table 4 Lagrange multiplier significance test of residual first- and second-order autocorrelation ( $p$ values in the table) according to different specifications

\begin{tabular}{|c|c|c|c|c|c|c|c|}
\hline \multirow[t]{2}{*}{ Period } & \multirow[t]{2}{*}{$\begin{array}{l}\text { Order of autocorrelation } \\
\text { of significance test }\end{array}$} & \multicolumn{2}{|c|}{ Filtered series } & \multicolumn{2}{|c|}{$\begin{array}{l}\text { Quadratic time } \\
\text { polynomial }\end{array}$} & \multicolumn{2}{|l|}{ No trend } \\
\hline & & $1 \mathrm{lag}$ & 3 lags & $1 \mathrm{lag}$ & 3 lags & $1 \mathrm{lag}$ & 3 lags \\
\hline \multirow[t]{2}{*}{$1630-1870$} & 1 st order & 0.00171 & 0.00004 & 0.00020 & 0.00078 & 0.00000 & 0.00823 \\
\hline & 2nd order & 0.00337 & 0.06977 & 0.00611 & 0.01564 & 0.00017 & 0.00491 \\
\hline \multirow[t]{2}{*}{$1630-1720$} & 1st order & 0.02975 & 0.00586 & 0.01800 & 0.01152 & 0.08883 & 0.08771 \\
\hline & 2 nd order & 0.21196 & 0.24518 & 0.21974 & 0.16605 & 0.15288 & 0.43443 \\
\hline \multirow[t]{2}{*}{$1721-1870$} & 1st order & 0.15621 & 0.14471 & 0.16005 & 0.09022 & 0.00373 & 0.01977 \\
\hline & 2nd order & 0.00519 & 0.71550 & 0.01787 & 0.67948 & 0.03409 & 0.30179 \\
\hline \multirow[t]{2}{*}{ 1871-1920 } & 1st order & 0.00005 & 0.18405 & 0.00032 & 0.29230 & 0.00064 & 0.25289 \\
\hline & 2 nd order & 0.00123 & 0.90436 & 0.01081 & 0.45979 & 0.04286 & $0.22521^{\mathrm{a}}$ \\
\hline
\end{tabular}

a This specification is unstable, since one of the eigenvalues of the companion matrix lies outside of the unit circle

Italics indicates specifications with no significant residual autocorrelation, i.e., with both $p$ values above 0.05

Figures 5 and 6 present the structural impulse response functions for 1630-1720 and 1721-1870, respectively. The figures also contain the 95 percent confidence intervals. They show that the strongest impact of harvest was after 1 year, which is significant for all vital rates in both periods.

For death rates in 1721-1870, there was also a significant impact from per capita harvests in the current year. Since the impact could not have been felt until the end of the year, it shows that death rates reacted to harvests quite immediately. The recursive order chosen in this study entails that birth and marriage rates did not have a contemporary effect on death rates, but only a lagged effect. For 1630-1720, the impact of harvest on the death rates was substantially stronger than in any of the subsequent periods. Harvest failures in 1 year caused increases in death rates in the subsequent 3 years. In 1721-1870, the impact of harvest on death rates receded substantially although there was still a significant impact of harvests on death rates in the years $1-3$.

For all vitals rates, the impact of harvests was reversed after 3-7 years. Such oscillation was strongest for marriage rates. For example, high marriage rates following good harvests were followed by lower marriage rates. This explains why the cumulative impact of harvests on marriage rates was quite weak. One explanation could be that high marriage rates caused the proportion of unmarried in the adult population to be reduced, which, in turn, decreased the number of marriages after some time. The impact on birth rates during the first years was not so different in 1630-1720 and 1721-1870, but since the oscillation weakened after 1720 , the cumulative impact substantially strengthened.

Table 5 displays the estimates of the cumulative structural impulse response function after 20 periods. The cumulative structural impulse response function (csirf) is not the same as the cumulative elasticity with harvest as the impulse. The 


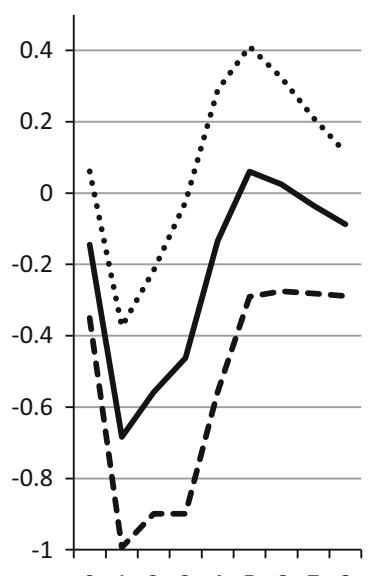

$\begin{array}{lllllllll}0 & 1 & 2 & 3 & 4 & 5 & 6 & 7 & 8\end{array}$

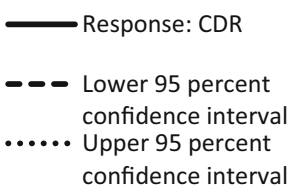

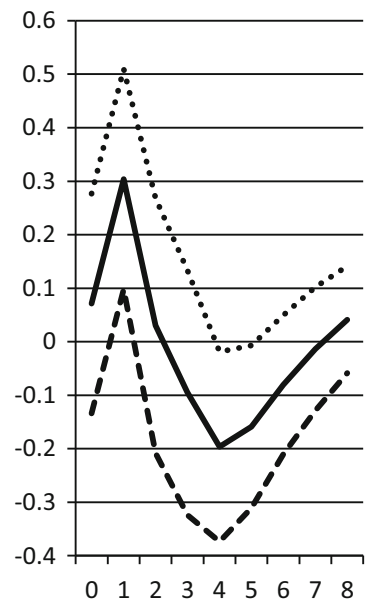

Response: MR

- - Lower 95 percent confidence interval

..... Upper 95 percent confidence interval

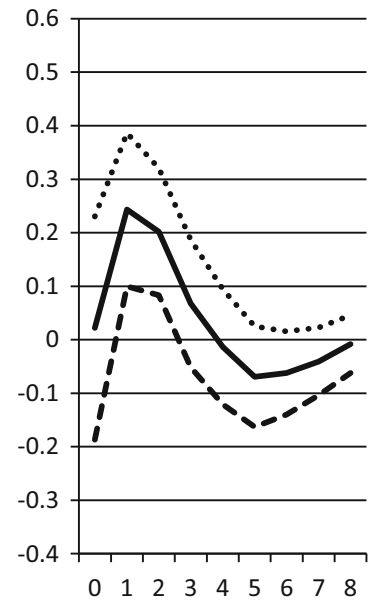

Response: CBR

- - Lower 95 percent confidence interval

..... Upper 95 percent confidence interval

Fig. 5 Estimated structural impulse response function, with harvests as the impulse, for the period 1630-1720 (vertical scale logarithms, horizontal scale years)
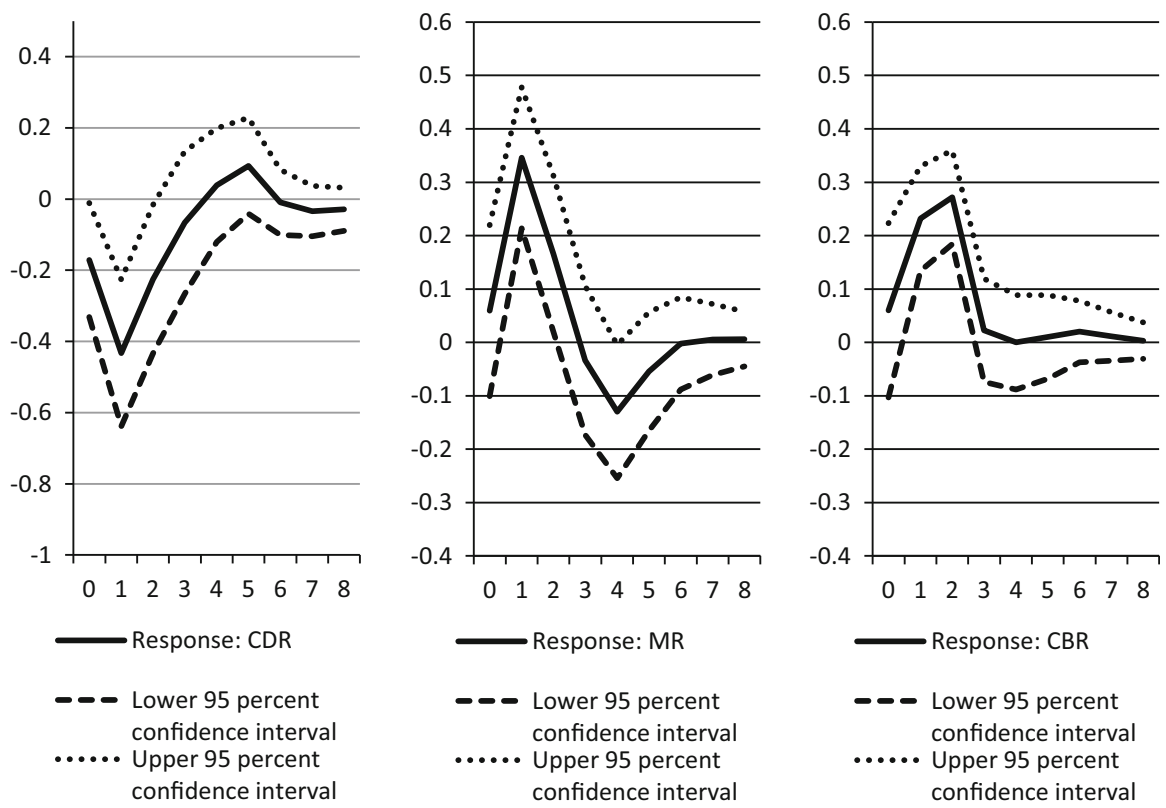

Fig. 6 Estimated structural impulse response function, with harvests as the impulse, for the period 1721-1870 (vertical scale logarithms, horizontal scale years) 
Table 5 Cumulative structural impulse response function and cumulative elasticity after 20 periods

\begin{tabular}{|c|c|c|c|c|}
\hline Period & $\begin{array}{l}\text { Response of harvests } \\
\text { to harvests } \\
\text { csirf } \\
\text { impulse: } h \\
\text { response: } h\end{array}$ & $\begin{array}{l}\text { Response of deaths } \\
\text { to harvests } \\
\text { csirf } \\
\text { impulse: } h \\
\text { response: } d\end{array}$ & $\begin{array}{l}\text { Response of } \\
\text { marriages to harvests } \\
\text { csirf } \\
\text { impulse: } h \\
\text { response: } m\end{array}$ & $\begin{array}{l}\text { Response of births } \\
\text { to harvests } \\
\text { csirf } \\
\text { impulse: } h \\
\text { response: } b\end{array}$ \\
\hline $1630-1870^{\mathrm{a}}$ & $\left(1.29^{* * * *}\right)$ & $\left(-1.60^{* * *}\right)$ & $(0.10)$ & $\left(0.38^{* *}\right)$ \\
\hline $1630-1720$ & $1.85^{* * * *}$ & $-2.45^{*}$ & -0.05 & 0.35 \\
\hline $1721-1870$ & $1.05^{* * * *}$ & $-0.86^{*}$ & 0.37 & $0.66^{* *}$ \\
\hline $1871-1920$ & $0.74^{* *}$ & -0.24 & -0.04 & -0.07 \\
\hline
\end{tabular}

$\dagger p<0.1 ;{ }^{*} p<0.05 ;{ }^{* *} p<0.01 ;{ }^{* * *} p<0.001$. The significance levels are based on the levels for the cumulative orthogonalized impulse response function after 20 periods. No significance levels are estimated for the cumulative elasticites (greyed area)

a The specification for 1630-1870 entails that there is strong autocorrelation in the error terms, which is why all values are put into parenthesis

Abbreviations see Table 1

former is the cumulative response of a one-unit shock of harvest on vital rates. However, part of the effect is through changing harvest in the next periods. For example, if a one-unit increase in harvest causes harvest also to increase by half a unit the next year, this also adds to the impact on the vital rates. Therefore, a oneunit increase in the harvest the current year is, in this example, a de facto one-and-ahalf unit increase in the harvests accumulated during the whole period. To estimate the cumulative elasticity of vital rates with respect to harvest, we have to divide the csirf with harvest as impulse and a vital rate as the response with the csirf with harvest as both impulse and response. This is presented in Table 6, which also compares the elasticities with the result from the DLM.

The cumulative structural impulse response function with harvest as impulse and response declined quite dramatically, from 1.85 in 1630-1720 to below unity in 1721-1870. Under the assumption of no positive impact on subsequent harvest, this value should be unity. Before 1630, shocks to harvests in 1 year had strong repercussions on later harvests, while after 1720 this was no longer the case. For the period 1630-1720, the decline substantially reduces the estimated cumulative elasticity of vital rates when compared to the cumulative structural impulse response function.

For death rates in 1630-1720, the estimated cumulative elasticity in Table 5, at -1.3 , is somewhat weaker than according to the distributed lag model. However, the change in 1720 was not as dramatic as according to the DLM. More importantly, after 1870 the cumulative structural impulse response function of per capita harvests on death rates was not significant, which is contrary to the result in Table 2.

Table 6 shows that for both marriage and birth rates, the cumulative elasticities significantly strengthened after 1720, while they disappeared after 1870 . However, despite the significant impact after 1 year, the cumulative elasticity of marriage rates was not significant in any of the investigated periods (see Table 5). The cumulative elasticity of birth rates was at 0.7 in 1721-1870, which was significant 
Table 6 Summary table of the estimated elasticities of vital rates with respect to per capita harvest for three sub-periods according to the distributed lag model (DLM) and structural vector autoregression (SVAR)

\begin{tabular}{|c|c|c|c|c|c|c|}
\hline & \multicolumn{2}{|c|}{$1630-1720$} & \multicolumn{2}{|c|}{$1721-1870$} & \multicolumn{2}{|c|}{$1871-1920$} \\
\hline & DLM & SVAR & DLM & SVAR & DLM & SVAR \\
\hline Crude death rate & -1.492 & -1.32 & -0.85 & -0.82 & -0.701 & -0.32 \\
\hline Marriage rate & 0.234 & -0.03 & 0.684 & 0.35 & -0.365 & -0.06 \\
\hline Crude birth rate & 0.324 & 0.19 & 0.515 & 0.63 & -0.002 & -0.09 \\
\hline
\end{tabular}

and stronger than according to the DLM, while it was not significant in any of the other sub-periods.

Overall, Table 6 shows that SVAR yields a similar picture as DLM: While after 1720 positive checks weakened, preventive checks strengthened. However, there is one crucial difference between the two models: While according to the DLM positive checks continued to exist until 1920, the SVAR analysis suggests that the Malthusian mechanism disappeared altogether after 1870.

\section{Putting the empirical findings in context}

There are several possible explanations for the decline in the elasticity of the crude death rate in Sweden after the 1710s. In particular, the years around 1650-1720 experienced severe economic difficulties. It took time for the economy to recover (Morell 1989). Climatic factors might also be important. A reconstruction of winter temperatures for Stockholm shows that a previous cold period beginning in the midsixteenth century ended around 1700 and that the 1730s was an unusually warm decade (Leijonhufvud et al. 2010). Other explanations for the decreased occurrence of severe mortality crises in Europe during the eighteenth century include a mutual adaptation between pathogen and host that decreased mortality levels during plagues, improved private and public hygiene and an enhanced system of transportation and market integration (Livi-Bacci 2007, 67).

The result of the present study that preventive checks disappeared after 1870 accords quite well with the description by Dribe (2008) of the fertility pattern in Sweden before 1880 as natural. Bengtsson and Dribe (2006) find that in Scania there was a strong fertility response to changes in food prices during the whole period 1766-1864. Klemp and Møller (forthcoming) similarly find that for the period 1777-1873 the preventive checks are highly significant with the expected sign.

The strong support for the existence of positive and preventive checks up to the nineteenth century can be contrasted to earlier research on England. Using VAR methods, Nicolini (2007) finds that the negative effect of real wages on mortality rates in England was significant only up to 1640, while the positive effect on fertility was significant only up to 1740 . Crafts and Mills $(2009$, 80) cannot find any evidence of positive checks even for the period 1542-1645 and conclude that 
preventive checks disappeared by the early seventeenth century. Recently, Rathnke and Sarferaz (2010) question this result, contending that by using a time-varying VAR model preventive and positive checks are made visible in the English data up to the nineteenth century. A problem with all of these studies, and a clear disadvantage to the present study, is that they use real wage as an indicator for living standards.

England was most likely earlier in its transition to a post- or late Malthusian economy. Compared with England (Wrigley and Schofield 1989, 531-535), the spikes in Swedish mortality rates up to the early eighteenth century were at a much higher level (see Fig. 1). Some European countries displayed a similar development as that in Sweden, with a marked decline in severe mortality crises during the course of the eighteenth century (Livi-Bacci 2007, 67). Nevertheless, as for Sweden, it is likely that other results could be found for England if elasticities were computed with respect to harvest or food production or if the series of crude death rate for England is upgraded during mortality peaks in light of the criticism directed against the demographic reconstruction of Wrigley and Schofield.

The decline in the sensitivity of mortality after 1720 may be surprising given that earlier Swedish studies show that there was a very strong dependency on cereal products in the eighteenth century, while animal products stood for only a small part of the diet (Morell 1986). However, per capita food consumption did not decline during the course of the seventeenth and eighteenth centuries, while GDP per capita increased somewhat despite the relatively fast population growth (Edvinsson 2013a). The significant growth in the size of the population during the eighteenth century was in itself a manifestation of a dynamic economy. Gadd describes Sweden as going through an agrarian revolution in the eighteenth and nineteenth centuries (Gadd 2000). Import of grains also dampened the impact of harvest fluctuations on death rates.

For Germany, Pfister and Fertig $(2010,48)$ find that positive checks substantially weakened after the 1810 s, which is not as visible in the Swedish material. Klemp and Møller (forthcoming) also find evidence for positive checks in Sweden for the period 1777-1873. The DLM reproduces the result by Galloway $(1994,24)$ that there were strong positive checks in Sweden after the industrial breakthrough (which he also argues was the case for France), while according to the SVAR model the positive checks were no longer significant after 1870 .

To some extent, the response of the marriage rate is a more direct indicator of preventive checks, since some of the responses of birth rates, at least in the shortterm, reflected changed nutritional standards rather than active preventive behavior. The present study indicates that the elasticity of the marriage rate displayed a similar trend as the elasticity of the birth rate. The very weak, and insignificant, elasticity of the marriage rate in 1630-1720 supports the view that there was a hidden demographic transition between the seventeenth and eighteenth centuries as argued by some Swedish historians. Higher death rates tended to increase the number of marriages. Lower life span induced a lower age at marriage. When the mortality crises attenuated after the $1710 \mathrm{~s}$, preventive checks became more predominant. 


\section{Conclusions}

Malthus' original formulation of his model of preventive and positive checks related vital rates to the production of land, not without good reason. The present study argues that one of the most important indicators used by present-day Malthusiansdaily real wage-could be problematic when analyzing the Malthusian world. Instead, this study investigates the short-term Malthusian mechanism by using a series of harvests transformed into the production of per capita calories.

The present study uses different models to estimate the cumulative elasticities of vital rates: DLM, ARMAX and SVAR. In addition, various specifications are used concerning the underlying trends and the number of lags included. The main result is, however, robust to the specifications made. All models support the weaker version of the Malthusian model. In the pre-industrial Sweden, there was a shortterm Malthusian mechanism in terms of strong positive and preventive checks, without implying that per capita income declined due to population growth. Through the effect on death and birth rates, natural population growth was strongly affected by harvest fluctuations. The impact of harvests on various demographic indicators was stretched over several years. The strongest impact was from the harvests lagged by 1 and 2 years. All major spikes in death rates were preceded by 1 or 2 years of harvest failures. An important finding is that structural breaks occurred around 1720 and 1870, although it is also possible that a structural break occurred in 1820 .

The results are somewhat sensitive to which model is applied. The distributed lag model supports the finding of Galloway (1994) for France and Sweden that positive checks existed up to 1920 , while the SVAR model does not support that finding. In 1630-1720, the cumulative elasticity of the crude death rate was stronger than in any subsequent period according to all the specifications used in this study, reflecting the mortality crises occurring in this period. Up to the early eighteenth century, the cumulative elasticity of death rates was much stronger than of birth and marriage rates. A fundamental change occurred after 1720. Preventive checks were initially strengthened, while they disappeared after the rise of the industrial society in the final decades of the nineteenth century, in accordance with earlier findings by Swedish researchers on changing fertility patterns. This development also accords quite well with the prediction of the unified growth theory that in the initial phase of technological acceleration (which Swedish agriculture experienced in the eighteenth century) preventive checks strengthened, while positive checks attenuated (Galor and Weil 2000). However, to what extent there was a long-term adjustment of vital rates and population growth to harvest output needs further investigation.

The demographic transition implied that first death rates went down, but not birth rates, which accelerated population growth. Second, birth rates also declined, which completed the transition (Lee and Anderson 2002). Even if the lower floor of the crude death rate did not start to decline until the 1820s and 1830s (see Fig. 1), the transformation in the elasticity of death rates a century earlier was critical.

This paper shows that the Swedish economy in the seventeenth century deviated from that of the English economy. According to the data of Wrigley and Schofield, 
England had already embarked on a similar transformation much earlier than Sweden. Based on English data, Nicoloni (2007) concludes that "perhaps the world before Malthus was not so Malthusian." Early modern Swedish data can probably better illuminate the dynamics of the agrarian economy, given the special features of England as the first country experiencing an industrial revolution. Furthermore, the reliability of the English data has been questioned. Even if England has a continuous series of vital rates that goes further back in time than for any other country, the reliability of the Swedish data is superior for the second half of the eighteenth century to any other country due to the early official statistics.

Acknowledgments The author is grateful for financial support from Jan Wallanders och Tom Hedelius Stiftelse, Ragnar Söderbergs stiftelse, Riksbankens Jubileumsfond, Swedish Collegium for Advanced Study, and Vetenskapsrådet. For comments the author wants to thank especially Tommy Bengtsson, Olle Krantz and Lennart Schön.

Open Access This article is distributed under the terms of the Creative Commons Attribution 4.0 International License (http://creativecommons.org/licenses/by/4.0/), which permits unrestricted use, distribution, and reproduction in any medium, provided you give appropriate credit to the original author(s) and the source, provide a link to the Creative Commons license, and indicate if changes were made.

\section{Appendix}

Data on population, mortality, fertility and marriage rates are from a previous study (Edvinsson 2015). These series are based on data from Palm (2000, 2001) and Heckscher (1936). For the eighteenth century, Palm most likely underestimates the size of population and the vital rates. For 1630, the population within the borders of Sweden is raised from 0.912 to 1.12 million, while for 1700 it is raised from 1.373 to 1.44 million compared to Palm. The trends in vital rates and total population are substantially revised, while annual fluctuations closely follow the data of Palm. From the mid-eighteenth century, the population data are from Statistics Sweden (1999).

The series of per capita harvest is from previous published studies (Edvinsson 2009, 2013a, b). Krantz and Schön (2012) present an alternative agricultural series for the early modern period based on the so-called demand approach, but it does not distinguish between harvests and animal products. From 1802, the harvests are derived from reports on the yield ratios (gross harvests divided by seed) of different grains for all Swedish 24 counties. The absolute levels of harvests are uncertain for the nineteenth century, but annual fluctuations are of high reliability due to the detailed make-up of the primary material.

For the period from 1802, gross harvests are transformed into calories. One kilogram of wheat is assumed to contain $3365 \mathrm{kcal}, 1 \mathrm{~kg}$ of rye $3433 \mathrm{kcal}, 1 \mathrm{~kg}$ of barley $3404 \mathrm{kcal}, 1 \mathrm{~kg}$ of oats $3369 \mathrm{kcal}, 1 \mathrm{~kg}$ of dredge $3387 \mathrm{kcal}, 1 \mathrm{~kg}$ of peas, beans, or vetch $3285 \mathrm{kcal}, 1 \mathrm{~kg}$ of potatoes $670 \mathrm{kcal}, 1 \mathrm{~kg}$ of sugar beets $430 \mathrm{kcal}$, $1 \mathrm{~kg}$ of oil plants $2700 \mathrm{kcal}$ and $1 \mathrm{~kg}$ of triticale $3399 \mathrm{kcal}$.

For the period before 1802, the series of grain production is undifferentiated, and the assumption is that their calorie content followed their volume value. For the 
period before 1802, the volume value (i.e., the nominal value deflated by the price index of grains) of harvest is constructed from three indicators: tithes, subjective harvest estimates and grain prices. Grain prices are not a direct indicator of harvest fluctuations. Nevertheless, in a previous study by the author it is shown that for the early nineteenth century a regression model where grain prices for two consecutive years are included as independent variables, together with another indicator of harvests, can explain over $85 \%$ of the variance in annual harvest fluctuations. It is only for later periods that grain prices were weakly related to harvests (Edvinsson 2009).

The wage series (in Fig. 4) is spliced from three series, where the nominal wage is deflated by the Consumer Price Index (Edvinsson and Söderberg 2011): for 1630-1732, the day rate of male manual labor in Stockholm (Söderberg 2010); for 1732-1914, the day rate of male agrarian labor in the whole country (Jörberg 1972, vol. 2); and from 1914, the hourly wage of male workers in industry (Prado 2010). The standard deviations of the first and third series are adjusted to conform to the standard deviation of the series of $1732-1914$, by using the ratios of standard deviations in annual logarithmic changes for overlapping periods.

For 1732-1913, grain prices (in Fig. 4) are based on the average national price of various grains (Jörberg 1972, vol. 2) using quantity weights from the early twentieth century. For the period 1913-1949, the quantity weights are from 1913. For the period before 1732, the series is mostly based on the prices of rye and barley (Edvinsson 2012). The nominal price is transformed to being expressed in grams of gold.

\section{References}

Allen R (2001) The great divergence in European wages and prices from the middle ages to the first world war. Explor Econ Hist 38:411-447

Åmark K (1915) Spannmålshandel och spannmålspolitik i Sverige 1719-1830. Stockholms högskola, Stockholm

Bengtsson T (2004) Living standards and economic stress. In: Bentsson T, Campbell C, Lee JZ (eds) Life under pressure. Mortality and living standards in Europe and Asia, 1700-1900. MIT, Cambridge, pp 27-59

Bengtsson T, Broström G (2011) Famines and mortality crises in 18th to 19th century southern Sweden. GENUS LXVII:119-139

Bengtsson T, Dribe M (2006) Deliberate control in natural fertility population: Southern Sweden, 1766-1864. Demography 43:727-746

Bengtsson T, Ohlsson R (1985) Age-specific mortality and short-term changes in the standard of living: Sweden, 1751-1859. Eur J Popul 1:309-326

Chiarini B (2010) Was Malthus right? The relationship between population and real wages in Italian history, 1320-1870. Explor Econ Hist 47:460-475

Clark G (2007) A farewell to Alms: a brief economic history of the world. Princeton University Press, Princeton and Oxford

Crafts N, Mills T (2009) From Malthus to Solow: how did the Malthusian economy really evolve. J Macroecon 31:68-93

Diebolt C (2016) Cliometrica after 10 years: definition and principles of cliometric research. Cliometrica $10: 1-4$

Dribe M (2003) Dealing with economic stress through migration: lessons from nineteenth century rural Sweden. Eur Rev Econ Hist 7:271-299 
Dribe M (2008) Demand and supply factors in the fertility transition: a county-level analysis of agespecific marital fertility in Sweden, 1880-1930. Eur Rev Econ Hist 13:65-94

Dribe M, Olsson M, Svensson P (2011) Production, prices and mortality: demographic response to economic hardship in rural Sweden 1750-1860. Unpublished paper, presented at the European Historical Economics Society. Dublin

Eckstein Z, Schultz TP, Wolpin KI (1984) Short-run fluctuations in fertility and mortality in pre-industrial Sweden. Eur Econ Rev 26:295-317

Edvinsson R (2009) Swedish harvests 1665-1820: Early modern growth in the periphery of European economy. Scand Econ Hist Rev 57:2-25

Edvinsson R (2012) Harvests and grain prices in Sweden 1665-1870. Agric Hist Rev 60:1-18

Edvinsson R (2013a) Swedish GDP 1620-1800: Stagnation or Growth? Cliometrica 7:37-60

Edvinsson R (2013b) New annual estimates of Swedish GDP in 1800-2010. Econ Hist Rev 66:1101-1126

Edvinsson R (2015) Recalculating Swedish pre-census demographic data: was there acceleration in early modern population growth? Cliometrica 9:167-191

Edvinsson R, Söderberg J (2011) A consumer price index for Sweden 1290-2008. Rev Income Wealth 57:270-292

Gadd CJ (2000) Den agrara revolutionen 1700-1870. Natur och kultur/LT, Stockholm

Galloway PR (1988) Basic patterns in annual variations in fertility, nuptiality, mortality and prices in preindustrial Europe. Popul Stud: J Demogr 42:275-303

Galloway PR (1994a) A reconstruction of the population of North Italy from 1650 to 1881 using annual inverse projection with comparisons to England, France, and Sweden. Eur J Popul 10:223-274

Galloway PR (1994b) Secular changes in the short-term preventive, positive, and temperature checks to population growth in Europe, 1460-1909. Clim Change 26:3-63

Galor O, Weil DN (2000) Population, technology, and growth: from Malthusian stagnation to the demographic transition and beyond. Am Econ Rev 90:806-828

Gráda CÓ (2001) Markets and Famines: evidence from Nineteenth-Century Finland. Econ Dev Cult Change 49:575-590

Heckscher E (1936) Ekonomisk-historiska studier. Bonnier, Stockholm

Hoffman P (1991) Land rents and agricultural productivity: the Paris Basin, 1450-1789. J Econ Hist 51:771-805

Jörberg L (1972) A History of Prices in Sweden 1732-1914. Gleerup, Lund

Klemp M (2012) Prices, wages and fertility in pre-industrial England. Cliometrica 6:63-77

Klemp M, Møller NF (forthcoming) Post-Malthusian Dynamics in Pre-Industrial Scandinavia. Scand J Econ

Krantz O, Schön L (2012) The Swedish economy in the early modern period: constructing historical national accounts. Eur Rev Econ Hist 16:529-549

Larsen U (1987) Determinants of short-term fluctuations in nuptiality in Sweden, 1751-1913: application of Multivariate ARIMA Models. Eur J Popul 3:203-232

Larsson D (2006) Den dolda transitionen: Om ett demografiskt brytningsskede i det tidiga 1700-talets Sverige. Gothenburg University, Gothenburg

Lee R, Anderson M (2002) Malthus in state space: macro economic-demographic relations in English history, 1540 to 1870 . J Popul Econ 15:195-220

Leijonhufvud L, Wilson R, Moberg A, Söderberg J, Retsö D, Söderlind U (2010) Five centuries of Stockholm winter/spring temperatures reconstructed from documentary evidence and instrumental observations. Clim Change 101:109-141

Livi-Bacci M (2007) A Concise History of World Population. Wiley-Blackwell, Cambridge, Mass

Maddison A (2007) Contours of the world economy, 1-2030 AD: essays in macro-economic history. Oxford University Press, Oxford

Malthus T (1985) An essay on the principles of population. Penguin Books, London

Mokyr J, Voth HJ (2008) Understanding growth in Europe, 1700-1870: theory and evidence. In: Broadberry S, O'Rourke K (eds) The Cambridge economic history of modern Europe, vol 1. Cambridge University Press, Cambridge, pp 4-42

Møller NF, Sharp P (2014) Malthus in cointegration space: evidence of a post-Malthusian pre-industrial England. J Econ Growth 19:105-140

Morell M (1986) Eli F. Heckscher, utspisningsstaterna och den svenska livsmedelskonsumtionen från 1500-talet till 1800-talet: Sammanfattning och komplettering av en lång debatt. Uppsala

Morell M (1989) Studier i den svenska livsmedelskonsumtionens historia: Hospitalhjonens livsmedelskonsumtion 1621-1872. Uppsala University, Uppsala 
Nelson M (1988) Bitter bread: the famine in Norrbotten 1867-1868. Uppsala University, Uppsala

Nicolini E (2007) Was Malthus right? A VAR analysis of economic and demographic interactions in preindustrial England. Eur Rev Econ Hist 11:99-121

Palm LA (2000) Folkmängden i Sveriges socknar och kommuner 1571-1997: Med särskild hänsyn till perioden 1571-1751. L. A. Palm, Gothenburg

Palm LA (2001) Livet, kärleken och döden: Fyra uppsatser om svensk befolkningsutveckling 1300-1850. L. A. Palm, Gothenburg

Persson KG (2008) The Malthus delusion. Eur Rev Econ Hist 12:165-173

Pfister U, Fertig G (2010) The Population History of Germany: Research Strategy and Preliminary Results, MPIDR Working Paper WP 2010-035

Prado S (2010) Nominal and real wages of manufacturing workers, 1860-2007. In: Edvinsson R, Jacobson T, Waldenström D (eds) Historical monetary and financial statistics for Sweden: exchange rates, prices and wages 1277-2008. Sveriges Riksbank and Ekerlids, Stockholm, pp 479-527

Rathke A, Sarferaz S (2010) Malthus was right: new evidence from a time-varying VAR. Institute for Empirical Research in Economics, University of Zurich, Working Paper No. 477

Razzel P (1993) The growth of population in eighteenth-century England: a critical reappraisal. J Econ Hist 53:743-771

Rebaudo D (1979) Le mouvement annuel de la population française rurale de 1670 a 1740. Population 34(3):594-596

Söderberg J (2010) Long-term trends in real wages of labourers. In: Edvinsson R, Jacobson T, Waldenström D (eds) Historical monetary and financial statistics for Sweden: exchange rates, prices and wages 1277-2008. Sveriges Riksbank and Ekerlids, Stockholm, pp 453-478

Statistics Sweden (1999). Population development in Sweden in a 250-year perspective. Stockholm

Voigtländer N, Voth HJ (2009) Malthusian dynamism and the rise of Europe: make war, not love. Am Econ Rev 99:248-254

Willner S (2005) Hälso- och samhällsutvecklingen i Sverige 1750-2000. In: Sundin J, Hogstedt C, Lindberg J, Moberg H (eds) Svenska folkets hälsa i historiskt perspektiv. Statens folkhälsoinstitut, Stockholm, pp 35-80

Wrigley EA, Schofield R (1989) The population history of England 1541-1871: a reconstruction, paperback edn. Cambridge University Press, Cambridge 